\title{
Navigating Mandates: Teachers Face "Troubled Seas"
}

\author{
JEANNE COBB \\ Coastal Carolina University \\ STEPHEN SARGENT \\ Northeastern State University \\ CHITLADA PATCHEN
}

\begin{abstract}
This descriptive research study presents the voices of four participating teachers who share how mandates have affected their classroom practices and their students. The teachers describe how they have struggled to maintain effective best literacy practices within this "pressure cooker" accountability culture. They discuss tools and coping strategies used by literacy specialists and classroom teachers to deal with conflicts and communicate with multiple stakeholders. The article describes Phase III of a longitudinal investigation conducted by a research team from 10 states (Phase I and II), focusing only on the mandates data from the large-scale study. Three of the 11 original literacy professors of the team who began Phase I of this research, conducted a more in-depth investigation of four cases/teachers who represented varying stances in response to the mandates. A continuum of teacher responses to restrictive mandates is presented.
\end{abstract}

\section{Introduction}

During the past two decades, a reform movement has swept across the United States designed to improve public education and fix perceived weaknesses in our nation's schools. This reform movement has centered on accountability, holding teachers, principals, and school systems jointly responsible for student learning. The consequences of this push for reform have been monumental. Teachers must meet stringent requirements on many levels-national, state, local/school district. These mandates include implementing required curricula and instructional programs, strict time allocations for reading and writing, "high stakes" standardized tests and frequent classroom assessments, and specified professional development initiatives (Cheng, 2000; Crawford, 2004; Hayes, 2006; Hoffman, Assaf, \& Paris, 2001; Jennings, 1995; Jones et al., 1999; McColskey \& McNunn, 2001).

In this article we will hear the voices of four participating teachers who share how mandates have affected their classroom practices and their students. The teachers describe how they have struggled to maintain effective best practices within this "pressure cooker" accountability culture. They discuss tools and coping strategies used by classroom teachers, literacy specialists, and school administrators to deal with conflicts and communicate with multiple stakeholders. Listen to the voices of real teachers (pseudonyms used to protect confidentiality) as they share their struggles in "navigating the troubled seas" of teaching with mandates. 
Vignette \#1: JA

Every once in a while, I have to keep it fun. It is hard for me to do fun things everyday because I have to do the explicit systematic phonics instruction, but I try on Fridays with my first graders... I have a read aloud anthology... I use that every Friday with them. The kids, when we do word building everyday, they get tired of it. (JA, reading specialist and literacy coach)

As a reading specialist and reading coach with six years teaching experience working with 32 struggling readers in kindergarten and first grade, JA discusses mandates with a sense of resignation about following the directives, without questioning reasons for the mandates or the consequences for learners. Throughout the conversation, JA says she is required to implement explicit systematic phonics instruction daily and that this instruction consumes a large part of her instructional time. Much of her daily instruction primarily focuses on skill and drill.

\section{Vignette \# 2: Linda}

I feel very conflicted right now because these children really need help. I can't do that for them because there's too many that I have to teach...not only is there the literacy piece, but there's the math piece, science, and social studies. So I go in there every day and I teach, and I know that sometimes what I'm doing is not beneficial for everybody... It's a time thing. I can't do it because there's just no time. (Linda is a fourth grade teacher at an urban school)

At the time of our study, Linda had begun her seventh year of teaching fourth grade at a school with a predominantly non-English speaking population. She described her current teaching style as mostly "teacher-directed" due to the demands of new mandates. Linda experienced recurring frustration with what she knew her students needed and what she was directed to do with differentiated instruction. With all the demands placed on her, she felt there was never enough time to truly deliver effective instruction.

Vignette \#3: BG

There had been so much pressure on us to fix things in the past couple of years. I'm not sure it's sunk in yet, but maybe we can get back to teaching like we know is best and not just focus on the "list."[low performing children] (BG, Reading Specialist)

As a teacher in a school labeled "low performing", BG and her colleagues have come under scrutiny to improve their standardized test scores. BG, a reading specialist in the school, pulls small groups of students throughout the day to read. While she follows the required mandates, BG also supplements with multiple reading assessment and 
instructional techniques to ensure the best possible literacy instruction for all children. BG's school was required to implement Target Teach, a commercial program designed to align instruction and state tests in all grades (http://www.evannewton.com/TargetTeach/ TargetTeach.html). BG was also bound by state curriculum benchmarks and statemandated pre- and post-tests. All children were assessed using the Basic Early Assessment of Reading (BEAR) software (Riverside, http://www.riverpub.com/products/ bear/index.html). Finally, BG followed district mandated curriculum and pacing guides. These multiple mandates had an impact on BG's literacy assessment and instruction. She noted, "I give the assessments that my district mandates and also try to help teachers know how to give and interpret them." BG followed mandates and met student needs by supplementing instruction and helping teachers interpret mandated assessments.

\section{Vignette \#4: Melinda}

Our district is noted for being on top of things as far as innovative practices... how we have everything structured, knowing what we're supposed to be teaching. So, we're the district where everybody comes to look and see what to do...We definitely used what the state asked us to teach, of course, but we led the way in how to do it, [with] the methods, the materials. (Melinda, 1st grade teacher)

Melinda, a veteran first grade teacher in a diverse, low-income elementary school in the southwestern United States, talked in a matter-of-fact manner when describing how mandates have affected her teaching. Throughout the conversation, she focused on the positive aspects of high stakes testing as she described how the standardization of curricular objectives from the state made it easier for children to transfer from district to district. She stressed the importance of consistency and uniformity in the curriculum since her school population come from military families and is highly mobile. As a teacher for 24 years, Melinda is one of the participating teachers in our multi-case research project focusing on classroom teachers' experiences within the current environment of high stakes testing and mandates.

\section{Conceptual Framework/Theoretical Underpinnings}

Rooted in constructivism (Vygotsky, 1978), this study acknowledges that culture has a great impact on learning. Knowledge is not imparted to an "empty vessel", but instead constructed as students share knowledge and jointly develop understandings. However, the high stakes testing associated with current federal, state, and local mandates has played a prominent role in controlling how instruction is delivered in American schools today. While policy makers may embrace the idea of high stakes testing to "control" the educational system, this testing invariably results in a narrowing of the curriculum and a distinct reduction in the variety of instructional methods used. For example, the push for and implementation of "direct instruction" is in direct contrast to the constructivist approach to learning. Under such conditions, many teachers have felt 
significant pressure just to "survive" in the classroom doing whatever it takes to keep their jobs.

This study focuses on how teachers cope with new teaching situations and builds on the research of Bransford and Schwartz (1999) who suggest teachers' practice in the classroom to be generally indicative of the quality of the learning transfer that takes place from previous learning experiences to a new one. Bransford and Schwartz's focus on the quality of teacher education and learning transfer correlates with other research done on teachers in reading clinic experiences in teacher education programs. It suggests that teachers who are properly prepared in clinical situations develop better practices in their classrooms (Deeney et al., 2005; Freppon et al., 2006), become more reflective (Laster, Johnston, \& Rogers, 2006), are better able to think and adjust instruction while teaching, and are more effective in applying research when attempting curriculum adjustments (Cobb, 2001). In addition, the research of Hoffman and Pearson (2000) builds a strong case for educational experiences that provide developing teachers with models for knowledge transfer and engagement in critical, reflective thinking as essential to diagnostic teaching. This is the antithesis of a teacher preparation model of training only (i.e., spoonfeeding). For example, some teacher education programs have teacher candidates passively learning how to teach reading in a lecture format without the benefit of hands-on experiences until the semester of student teaching. Such a model of teacher education is a stark contrast to that promoted by Bransford and Schwartz (1999).

Johnson's (2007) theory of emotion also provides a research base for affective issues involved in understanding how participants negotiate their decision making to handle their job pressures and responsibilities. Johnson states that "emotions are key components of complex processes of bodily perception, assessment, internal monitoring, self-transformation, motivation, and action" (p. 66). As such, a teacher's ability to understand and manage his or her emotions within new and unfamiliar contexts also plays an important part in a teacher's ability to cope with and respond to the challenges of the modern day classroom.

This study, situated in these solid theoretical bases, investigated how teachers bring their learned experiences via constructivist approaches into real world settings and cope with the pressures of the mandated curriculum and testing programs in American schools today.

\section{Methodology}

This study was the outgrowth of a longitudinal, focused research study conducted by a group of literacy professors who are involved in directing on-campus and public school-based literacy clinics and labs at eleven sites in ten states. The researchers were interested in investigating the extent to which clinical training at the graduate and undergraduate levels has an impact on and transfers to classroom practices in an age of mandates. Drawing from Hoffman and Pearson's (2000) research on teaching versus training and Bransford and Schwartz' (1999) delineations of transfer as theoretical bases for our study, the team of researchers explored research designs to facilitate the collection of salient information. The initial prevalent research question guiding the multi-phased study was: What applications of best practice and transfer of theoretical knowledge, gained from clinical settings, do preservice and inservice teachers take into their 
classroom contexts following graduation? In the first phase of the current study (fall 2005), the researchers developed a survey to query graduates about the efficacy of graduate and undergraduate clinical reading programs. An electronic survey instrument (www.surveymonkey.com) was utilized focusing on key areas of assessment, instruction, leadership, coaching, and technology. The survey yielded a $40 \%$ response rate from 150 teachers at 11 university sites in 10 states (Deeney et al., 2005). The initial survey did not include mandates as a focus area; however, respondents in all 10 states mentioned mandates as having an impact on their use of literacy assessments and on their instruction. Furthermore, reading specialists who provided coaching and assumed other leadership roles within their schools noted the struggles with mandates as a constraining factor affecting their jobs and limiting the application of knowledge from their reading program's clinical experience. The quantitative and qualitative data analysis pointed to a new direction for Phase 2 of the research and the need for interviews with individual teachers who had responded to the survey to delve deeper into the issue of mandates raised by the teachers.

During the following year, each of the 11 researchers identified two to three graduates from their respective university reading programs, representing diverse stages in professional careers and job descriptions. The initial interviews (28) centered on the five themes: assessment, instruction, leadership, coaching, and technology. Each participant was asked to describe his/her context and to specifically address local, state, and federal mandates that impacted best practice. Space limitations prevent discussion of the findings from the large-scale research and interviews on all five areas of transfer (Freppon et al., 2006).

This article focuses only on the mandates data from the larger study. The specific research question dealt with what mandates were described and how they enhanced or inhibited transfer and application of knowledge of "best practice" gained in university literacy lab clinical experiences. In the spring of 2006, two researchers at separate university sites individually reviewed all 28 verbatim interview transcripts to find any specific reference to mandates and accountability. The researchers categorized those findings to identify the ways teachers described the mandates they faced and how those mandates limited or enabled them to apply theoretical knowledge from university clinic programs, using a constant-comparative method (Bogdan \& Biklen, 1992). Three categories initially were evident (federal, state, and local mandates-see Appendices A, $\mathrm{B}$, and $\mathrm{C}$ ). Further analysis revealed additional mandates dealing with professional development, commercial instructional programs, commercial assessments, naturalistic assessments, and curriculum approaches.

At this point in the study, refinement and an additional research question evolved, necessitating a return to the data. It was apparent that a distinct reoccurring theme in the interview data was the teachers' need to discuss their problems with mandates and how they deal with mandates. When confronted with the overwhelming struggles described by the teachers, the team of two researchers formulated a more specific research question: How do teachers, trained in "best practices" in university reading clinics, navigate around and cope with restrictive mandates in their classrooms and supervisory positions? In this next phase of data analysis, a third researcher at a different university site joined the research team (fall 2006). This researcher reviewed the verbatim interview transcripts to 
identify broad themes. At the same time, the two original researchers revisited the 28 interviews with a specific focus on the new research question. Triangulation occurred when the team of three researchers compared and contrasted findings from individual data analysis and the specific ways teachers were coping with the mandates in their schools. To accomplish this task, a constant-comparative method was again employed (Bogdan \& Biklen, 1992). All data sources were analyzed separately during and after the process of data collection in an effort to discern themes and trends pertaining to research questions (Merriam, 1998). The researchers triangulated the data sources to verify or refute potential patterns or trends, using conversational discourse analysis techniques to analyze the transcripts of recorded conversations. Analysis involved attending to what was said, how much was said, by whom, and for what purposes (Tannen, 1989; 2007).

Conversational discourse analysis involves analysis of language that goes beyond the sentence into the larger chunks of language as they flow together. The researchers transcribed and analyzed the informal conversations with the participants as text. Implied meanings from the conversational manner used by the speakers, the repetitions, the ways they strung their words together, the markers used to indicate pauses in thought processes are all nonverbal cues and were included in the conversational discourse analysis. Tannen (2007) believes that our personal worlds are revealed in the conversations we have with co-workers, family, and friends. As we delved into the transcribed conversations of the teachers in our study, much was revealed about the ways they are navigating difficult instructional climates.

In the final analysis of data, varying responses to local, state, and federal mandates became evident. A four-stage continuum was constructed based on the researchers' perceptions of teacher responses to display visually the ways the teachers were coping with the mandates.

\section{Results}

In our study, we found that regardless of the mandates a school was required to follow, mandates had a significant impact on curriculum and how instruction was delivered. Of major concern to teachers was how to cope with strict mandates while holding firm to their ideals and beliefs. Many teachers encountered what we might be described as "sailing in troubled seas." For these teachers, mandates significantly influenced curriculum and instructional practice at every level. They reported that scripted mandates limited their instructional practices. Many teachers felt compelled to abandon engaging and motivating instructional practices to prepare students to pass standardized tests. For them, students passing tests became the primary focus of what was taught in schools and by what standard. Other teachers in our study balanced the demands of mandates to "navigate the troubled seas" by supplementing mandated initiatives with a range of instructional practices.

Throughout the individual interviews, many participants noted challenges in implementing the mandates. A lack of resources to implement all the components of the mandates was commonly encountered. Many participants shared a concern about a lack of time to incorporate the naturalistic, authentic assessment strategies learned in teacher preparation programs (involving reading clinics) because of the testing mandates. However, those interviewed possessed a keen awareness of individual needs and 
attempted to focus on individual assessment when possible. The vast majority of those interviewed revealed that knowledge gleaned from clinical reading courses provided invaluable insight of naturalistic assessments and a confidence in the ability to provide for children's needs. The clinical experience also seemed to help practitioners supplement the mandated assessments with their own assessments.

How did teachers differ in their beliefs and practices? Was it their own learning experiences, school culture, personality or the mandates themselves that played a critical role on the teachers' performance, the students' achievement, and the school's performance? Investigating how mandates affected teachers with diverse perspectives helped the researchers better understand the impact of mandates on teachers and students today. When participating teachers talked about how mandates affected their teaching and classroom learning experiences, the responses generally fell into four categories.

Analysis of the teachers' varied responses revealed a disjuncture between clinical instruction and school-based mandates. This dissonance and teachers' responses could best be described as a continuum of stances based on the extent to which the teachers were able to blend assessment and instruction that was mandated with the "best practices" in assessment/instruction that they had learned in reading clinic/lab. The first stance of the continuum (far left) is the educator who truly agrees with the mandates and simply follows the required manuals exactly, using no other assessments or instructional procedures not outlined in the mandate. This teacher is compliant and often disregards prior learning in lieu of what he/she is told to do. The second stance of the continuum (second point from the left) is the teacher who follows the mandated instruction and assessments exactly, although he/she realizes children's needs may not be met with this plan alone. This teacher tends to offer reasons as to why no additional supplementary instruction or assessment is conducted. On the other end of the continuum (third stance/next point to the right) is the practitioner who follows the mandate(s), but also supplements with other reading assessments and often adapts instructional techniques to ensure optimal student learning. At the far right end of the continuum (fourth stance) would be the teacher who follows his/her knowledge, using skills not only to supplement and modify what is mandated, but often finds innovative and creative solutions to the dissonance encountered between his/her own philosophical belief system/university methodology and the restrictions of the accountability system. Figure 1 illustrates the four stances of teachers' responses to mandates.

Figure 1. The Four Stances of Teachers' Reponses to Mandates

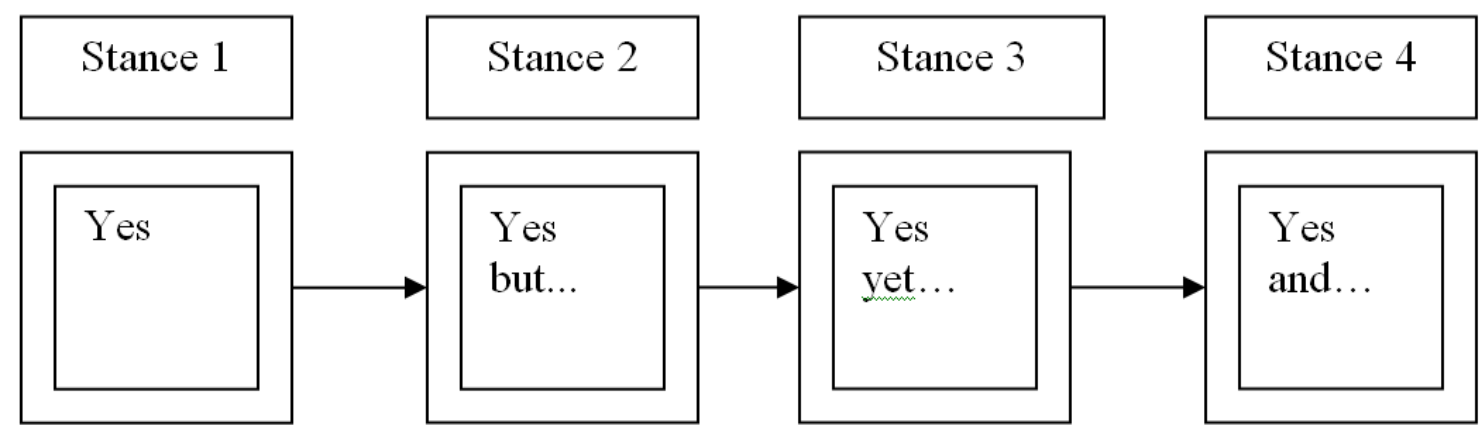


Data analysis revealed a connection to Johnson's Theory of Emotion (2007) in that it was apparent the meaning gained from participants' responses to their unique contexts or experiences was grounded in their emotions and sensory input. The teachers in our study who evidenced transformational stances 3 and 4 were highly engaged in the conversations about their instructional decisions. The meanings and rewards gained from their choices to go "beyond the mandates" appeared to be connected to an emotional response and "push back" against constraints that violated their sense of what was best for their students. This emotional response is obviously difficult to measure and describe but it is apparent when conversing with transformational teachers who are change agents.

\section{Limitations}

We would be remiss in proposing these categories as a way of viewing teachers' varied responses to mandates within the reform climate of public school classrooms without pointing to the problematic nature of continuums and categories in any research study. There are so many factors at work - teacher personality, emotional responses to authority figures, instructional time on task, administrative support, administrative leadership styles, the demographics of the school population-which often determine the strictness with which mandates are imposed. Our study did not afford the opportunities to delve deeply into other factors which may have influenced the stances taken by our participating teachers. We present the continuum merely as a starting point for other researchers to investigate how and why teachers respond to mandates in unique and personal ways and teachers are likely to fall at many points along the continuum and can possibly even be in transition from stance 3 to stance 4, for example. We see the continuum as a helpful visual for literacy teacher educators in presenting some common possible responses for teachers when faced with difficult instructional choices and to highlight more desirable stances that can be transformational. The continuum can also serve as a tool for self-reflection and evaluation as teachers struggle to interpret their own instructional decisions.

\section{Tools for Navigating Mandates}

\section{Case Study \#1: JA - "Yes!” (A compliant stance...)}

As a reading specialist and reading coach with six years teaching experience working with struggling readers in kindergarten and first grade, JA is illustrative of the type of teacher who would be situated at the far left of the continuum. JA would typically conduct instruction by strictly following the publisher's manual and fully complying with the principal's directives, using no other assessments or instructional procedures not outlined in the mandate. From her words, we may infer that there is total "buy-in" to a mandated assessment tool:

And the Dynamic Indicators of Basic Early Literacy Skills (DIBELS) assessment is something that I administer throughout the year in Kindergarten and um, they do use it in first grade...so I have been there to assist if they needed an extra hand. My primary reason for having the palm pilot and going to the training is 
Kindergarten. It is cool because... you pick a grade level and I am picking Kindergarten, [demonstrates the palm pilot] and it lights up!

It is apparent from JA's very detailed discussion of her palm pilot that she is a strong believer in the value and power of its use in her teaching. The focus is on the technology and its functions, but there is little mention of children and how the palm pilot guides her overall literacy instruction to help those children become independent and avid readers. JA reiterates that she believes that assessment guides her instruction, and she seems fascinated by the newly mandated tool. However, her thinking about assessment seems to center on the mandated DIBELS tests and the palm pilot provided by the grant to her school rather than on individual students and their specific needs and how the DIBELS data can be used for future instructional planning.

Teachers like JA sometimes express frustration, but typically comply willingly with all mandates. Although they may feel that their instruction lacks the excitement and the interactive elements that they would like to incorporate, the easiest strategy for them is to comply and to accept the mandates required in their contexts. JA seems to be an example of the path chosen by a large number of today's literacy teachers, the path of least resistance. These teachers are told what to believe, what to teach, how to assess, and what instructional methods to use. In spite of some conflicting philosophical issues and regardless of graduate classes in the university clinic, these teachers avoid deep reflective thinking and just do what is asked of them. They choose not to supplement, modify, or question the mandates imposed on them. Their coping tools are resignation, acceptance, and avoidance. Teachers who accept the mandates and avoid deep reflection choose these coping tools to be in compliance with the instructional approaches and assessments presented to them. Questioning the "status quo" would provide too much of a dissonance, and they are unwilling to deal with that dissonance.

\section{Case Study \#2: Linda - “Yes! But...” (Sees but cannot do, rationalization)}

Linda had a unique classroom situation and provides an example of the second stance, expressing concerns and frustrations with the inadequacy of the required mandates. However, Linda does not describe teaching in a way that reveals any movement to adapt or modify instruction to circumvent the mandates. She had 19 students in all, but eight of them were on an Individual Education Plan (IEP), and a special education teacher would come to work with her students for approximately two hours a day. In addition, at the time of our study, her school had just received a new district mandate for a teacher-directed reading program called Harcourt Anthology. Linda witnessed how the school tried to fit the Harcourt Anthology program into the already balanced literacy curriculum that they had used before. The new mandates created a degree of frustration for Linda and several of her colleagues in appropriating the new material into their instructional practice. In the following section, Linda's responses to the imposition of new curriculum mandates are discussed.

\section{Instructional practice}

As mentioned in the vignette, Linda admitted that her teaching style had become more of a "teacher-directed" approach due to the new Harcourt Anthology program. Her 
daily routine included a teacher directed read-aloud and some math exercises in the morning. She held guided reading and a 15 minute sustained silent reading (SSR) in the afternoon. She also tried to fit in science and/or social studies which complied with the mandated routines. Linda shared her thoughts about the Harcourt Anthology program and her teaching challenges:

This is all new and changing. Nobody's actually sat down and told us what they want us to do. We used to do a balanced literacy spelling. They've never told us that we're not supposed to be doing that anymore, but by word of mouth we're now allowed to do the Harcourt spelling. It's kind of up in the air. There really isn't a good program for spelling. However, Harcourt has a good vocabulary program.

The above quote indicates how new mandates that are quickly imposed or not clearly communicated can create a confusing teaching environment. Linda also added that she had to integrate new science and social studies lessons into her curriculum, and administer several new assessments. She said:

I hardly have time to teach all of them....and I have a wide range of student levels. I have to go with what I have to give a child an instructional program on their level, that's what they really need is a lot of [focused] work. It's not that I walk out the door at 2:50 p.m. every day, I certainly don't have time.

\section{Assessment Practice}

The school requires that teachers conduct an assessment at the beginning of the year. Teachers then need to write a personal literacy plan (PLP) for any child who performs $40 \%$ or below on that test. It is evident that Linda's assessment strategy is called "fast food." She thought that the assessment techniques she had learned in her university training were better to diagnose a child's strengths and weaknesses than the school's current mandated program. She believed that some of the newer mandated assessments, such as the Comprehensive Test of Phonological Processing (CTOPP), were not very helpful in assessing a student's true weaknesses. However, she didn't use the assessment techniques that she had learned in her clinical experience even though she believed them to be more effective to measure her students:

The stuff that I learned in the reading program, although I think those are better to diagnose child's difficulties...I don't have time to administer those.

Linda's case indicates that she knows what effective practices are, but she uses the tools of rationalization and excuse-giving to minimize the frustrations she is feeling. Linda is not unique in today's classrooms. Several teachers in the present study also said that limited time and the overwhelming number of mandated requirements prevented them from effective instructional delivery. 
Case Study \# 3: BG "Yes, yet...” (Compliance yet supplementing to meet individual needs...)

Teachers who adopt the third stance in response to imposed mandates are constantly searching for ways to ensure that the literacy needs of their students are met. BG serves as an instructional specialist in an urban school district and an example of this stance. This school serves a predominantly low-SES population and has a high minority population. Over the past five years, high mobility has been evident. Her school has been barraged with mandates from the federal, state, and local level. Several years ago, BG's school was placed on the state's "low performing" list, meaning that it did not meet state standards. If such a situation is not rectified, serious consequence might ensue. Thus, the pressure at this school mounted even more. Working with Pre-K through fifth grades, BG has a pull-out program for 45 students and also served as a reading coach for the thirty teachers of her building.

Even faced with these circumstances, BG remained optimistic. When questioned about mandates, she noted that mandates were simply a part of her job. However, BG was optimistic in her replies. For example, when discussing Target Teach (a district mandated program - see http://www.evansnewton.com/), BG stated, "This year, I have a lot more Target Teach to contend with...having some of these kids who are so low, succeed, is big in my role. I can work with them as well as their teachers to make a difference. If I can only help one kid it's all worth it." A positive, realistic attitude is perhaps BG's greatest coping strategy as she "sails the troubled seas" of mandates.

Using multiple resources and methods is another coping strategy BG employs to cope with mandates. Unlike JA, BG uses what is required, yet she also uses what she knows is needed to help children read. For example, a certain literacy program (basal) is mandated for the primary grades. To this end, BG has the phonics cards mounted on the wall that accompany this basal. Instead of only having those available (strict adherence to the mandates), BG noted that she also has "many 'strategy posters' on the walls for older kids." Another way BG does this is through literature. In addition to the required readers, BG provides a wealth of authentic children's literature. She remarked, "Books are readily available...I have many leveled readers and books sets." BG truly knows the importance of a print-rich environment and is passionate about this ideal. Instead of dismissing this knowledge in the face of mandates, BG both meets the mandate and incorporates what she knows and believes is crucial for optimal literacy development. These examples show how a teacher can use what is required but also use other materials that will be helpful for learning.

From her graduate reading program's strong knowledge base and her own continued learning, BG has constructed a wealth of knowledge on how best to teach reading. Having such an understanding is in fact a coping strategy for dealing with mandates. The more BG has learned about teaching reading, the better she feels she is able to teach, even amidst required methods, curriculum, and assessments. BG noted,

Again, reading clinic really prepared me for this part of the job. Working in the clinic, especially in the second one was helpful. Coordinating parent meetings, coaching in the clinic, coaching the undergraduate new teacher and everything we 
did made this part of the job easier. I've noticed that I was able to jump right in and do this compared to some of the other coaches-you know-those in other buildings who have trouble with this.

BG's focus is always on the individual learner. Thus, having a firm theoretical foundation is crucial to the teacher faced with mandates.

Searching for new ideas, implementing these in her classes, and sharing them with teachers helped BG cope with mandates. BG noted, "I had to figure out how to merge that theory stuff into actual lessons. Since the parents and the kids were both there expecting great things, I figured whatever I did better work. This [graduate reading program] really got me ready for my role I have now." BG often tried to find materials that matched her students' interest and proficiency, and use these along with required curriculum. She also found it very useful to share such materials and methods with other teachers in the same predicament. BG mentioned, "I present a lot of workshops for teachers in our building. This year I did a summer workshop on balanced reading and how teachers can start using it. I am doing some coaching now and trying to follow up." Unlike JA who simply took what the school provided and used it solely, BG uses such material but goes much further to ensure students and teachers are able to be successful.

BG is a teacher who faced many mandates. With BG's guidance and support, and the hard work of all teachers, children, and parents, her school was removed from the "low performing" list. Her coping strategies proved useful not only for her but for other teachers at her school site. BG is a teacher whose stance helped her entire school community face mandates that alone could have been devastating. While BG and many other teachers have in fact been doing the right things for learners all along, she remains hopeful that others who have not shared her same stance will do so in the future.

Case Study \# 4: Melinda "Yes, and!” (A child-centered, innovative stance...)

"Put children first and let your heart be your guide..."

Stance four teachers provide examples of effective coping strategies that move beyond federal policies or procedures. These teachers took a leadership role in their schools and engaged in instructional practices rooted in research-based "best practice." They worked to show others how to balance the demands of educational mandates and best practices in instruction when they believed there was a disjuncture between the two. Melinda is an exemplar of this stance. She is able to not only supplement and modify what is mandated, but often finds innovative and creative solutions to the dissonance encountered between her own philosophical belief system/university methodology and the restrictions of the accountability system.

Melinda, an experienced first grade teacher in a diverse, low-income elementary school in the southwestern United States, is an example of a teacher who would be placed at the far right end of the continuum. She responded to the researcher's question about how mandates have affected her teaching in a positive manner. She definitely was realistic about the impact of No Child Left Behind and noted that she felt pressure to get her students "ready" for the tests they would be taking later in their educational careers. Yet, she seemed to view the standardized testing mandates as just "part of the job" and 
described her instruction as based on an intuitive sense of what's best for each individual child, coupled with years of "on the job" training and "kid-watching."

In her 24 year career in education, Melinda has taught a variety of grade levels, and has also worked as a reading support person/coach for kindergarten-second grade teachers. Melinda declares she loves the first graders and the rewards of seeing their amazing literacy growth throughout the school year. She believes that if she does her job, students will perform well and be successful on their standardized tests. When discussing children's progress, she seems to be totally comfortable with their achievement levels and their abilities to succeed on mandated assessment measures, stating:

They are [right where they need to be]. These are really super readers. Of course, the more advanced they are, the more fluency they have, the more comprehension they have, the less time they have to[spend to]...figure out words [decode] and what they mean. So we have more time to do other things with the book and the words within it.

Melinda's coping strategies for dealing with mandates forced upon her are quite different from the teachers who focus on the mandates or the latest highly acclaimed program. Melinda's focus is on the learner and what she knows about children and how they learn best. It can best be summarized as a learner-centered view (Melinda) versus a program/assessment centered view (JA). Like JA, Melinda complies with the mandates, but differs from JA in that she does not blindly accept and follow. Melinda never loses sight of the importance of individualized, differentiated instruction and the need to meet each learner's needs. Intervention for struggling readers is a major component of her literacy program in her classroom and supplementary strategies are part of the normal routine. It is a total commitment to go beyond what is expected and to find a prescribed best path to literacy for each child.

Melinda is typical of teachers who draw on several resources or tools for strength to navigate around and through the mandates, making their classrooms exciting places for learning. One strategy used by Melinda to cope with the mandates is applying the mandates only to the learners for which they are appropriate. If it does not fit some of her learners, she chooses to implement it only for those children who can be successful with it. For example, Melinda's response about using Accelerated Reader, a program required in her local school district, is matter of fact and confident, "I used AR, but I didn't use AR with my other non-readers... Well you can't use AR if they're not reading".

Melinda realizes that she is competent to make instructional decisions that may vary from the requirements. She does not "force" all children to fit into an uncomfortable mold. She relies on her own knowledge of children's developmental stages and literacy abilities to make sound instructional judgments. For Melinda, disjunctures are resolved by relying on her sound theoretical frame of reference and trusting in her own judgment, formed from years of experience and advanced study. At the same time, she is prepared to use current research about assessment and instruction to defend her decisions to colleagues and administrators who may question her decisions.

Another strategy that aids Melinda in coping with the mandates is supplementing and modifying instruction and making time to do it. She finds this time by being highly 
organized in her planning and using every valuable minute for instruction. Every guided reading group has a special notebook with plans, anecdotal notes, and running records for each child in the group. Melinda mentioned that the impetus for this decision came from her graduate literacy assessment course:

Well, I remember when I was doing the camp, [graduate literacy assessment course] we did things in the camp that I wasn't able to do here, but I wanted to. You know, my running records and more one on one. Of course, you know, time is limited, but it gave me an encouragement to know these are possibilities.

And of course, I give one to one help with all my children as much as I can with writing also ... to make writing make sense.

She discussed how she makes time to help a struggling student, "Within the classroom, just when other kids are working... For a few minutes, you know, whatever we're working on. If we're writing, I'll sit right next to him, and work with him....".The interactions with other highly motivated teachers in graduate school and in a different setting, as she was experiencing first-hand the benefits of individualized assessments and individualized instruction, gave Melinda the courage to try something new. The planning notebook enabled her to implement the additional individualized assessment organized around guided reading groups because she was focusing on more structure, more advanced planning, and creating time within her day's already packed schedule for what she considered important. In her words, "I think it [the summer literacy camp experience in the graduate class] gave me more confidence in working with children, not that I don't have that already, but just [gave me] the "go for it" attitude".

Melinda was cognizant of the fact that one of the ways she gained courage to navigate through the mandates was through additional advanced training in literacy as she pursued the graduate degree. This knowledge instilled confidence and gave her time to reflect on her own practice, finding new and creative ways to meet individual student needs within a mandated curricular framework. It also gave her the courage and impetus to follow her own sound instructional judgment. Being in the learning community of a graduate clinical course with the feedback from professor and colleagues instilled confidence for Melinda to go back to her own classroom and be innovative within the confines of the mandates.

In summary, there is no doubt that Melinda feels compelled to do what is necessary to meet the required mandates imposed by the federal, state, and local authorities, but she employs a number of coping strategies or tools that help her to navigate successfully through the mandates. She uses self-questioning as a guide for every instructional decision: "What is best for each child? How can I make my classroom the most positive learning environment for these children who are in my care? She is student-centered and is committed to one-on-one instruction and meeting individual student needs. She does not hesitate to use a sound theoretical research base coupled with the knowledge gained through her experiences to supplement and modify her classroom instruction within the confines of required mandates. Melinda loves to share her expertise and her children's accomplishments with other educators. One of her most powerful coping tools is the confidence she has gained from this sharing and from watching her 
children succeed, year after year. She is passionate about research and best practice in literacy, believing that she is obligated to provide the best possible instruction for each child entrusted to her care. This mindset of "lifelong learning" is also a coping tool that serves her well.

Melinda's response to mandated curriculum objectives and teaching within an accountability climate of pressure and constraints is pragmatic. She follows the old adage, "where there's a will, there's a way." Simply stated, she believes that mandates are problematic, and she can overcome the constraints. She believes that standardized tests and the mandated curriculum are simply insufficient for narrowing the achievement gap between affluent children with strong literacy traditions in their homes and those children growing up in poverty. She is an innovative and caring teacher who lets her heart be her guide.

What we Learned/Implications for Preparing Quality Teachers...

In summary, the cases of JA, Linda, BG, and Melinda reflect many of the challenges confronting today's teachers regarding mandates in the classroom. As we consider which responses to such mandates seem most productive, the latter two cases present examples we encourage teachers to employ.

This article explored how federal, state, and local mandates affect educational practices, in particular, how teachers who were graduates of university reading clinic and literacy lab programs applied and transferred knowledge from those programs to their real-world classrooms. The testimonies of participating teachers reflect the difficulties that educators face in navigating the ever-changing classroom environment created by government rules and regulations. High-stakes testing has influenced educational practices, and in some circumstances led to negative instructional cultures in schools. There is a need to prepare reading teachers to deal with the demands of mandates and societal change strategically.

One challenge that persists in the United States is to reconcile the knowledge and instructional practices being taught to teachers in many universities with what local, state, or federal governmental agencies are mandating that teachers do in the classroom. Teachers may often find themselves in doubt over how far to go in order to comply with federal, state, or local mandates or assessments when they feel that different instructional methods or means would be more appropriate for many of the students in their classrooms. This conflict challenges both new and veteran teachers. Teachers who lack confidence, particularly new teachers, who are in the process of transitioning from being student teachers to being professional classroom teachers, must make decisions about instructional practice. They often feel pressured to choose between complying with government and/or school mandated agendas or teaching what they were taught through their teacher education program (Hoffman et al., 2005).

Studies have shown that veteran teachers respond to the mandated changes easier than new teachers (Buly \& Rose, 2001; Snow, Griffin, \& Burns, 2005). They often have more experience and tools in their repertoire which enable them to work within and around new school policy to meet requirements but not greatly compromise their instructional techniques or strategies. Effective veteran teachers generally do not let such pressure divert them from their instructional goals regarding the students' needs (Buly \& 
Rose, 2001). This reality should draw our attention to how well teacher education programs are preparing preservice and in-service teachers to anticipate and adapt to the ever-changing conditions in the classroom. The mandates of today may not be the mandates of tomorrow. The administration of today will not be the administration of tomorrow. There is a need to determine what is essential for prospective reading teachers to know, and how teacher education programs can equip student teachers to adapt their knowledge and skills to the situations in which they find themselves.

Hoffman and Pearson (2000) claim that teaching teachers of reading is to ultimately "help teachers develop the personal and professional commitment to lifelong learning required by those teachers who want to confront the complexities and contradictions of teaching" (p. 36). Thus, teacher education programs need to structure the curriculum in ways that help teachers learn how to be life-long learners. The programs should prepare developing teachers to see that their development goes beyond the confines of the classroom or school, that becoming a lifelong learner helps them renew and refresh their teaching practice. In addition, teacher education programs should expose developing teachers to in-depth discussions on policy, practice, and research related to the teaching of reading. Student teachers need to be aware of the controversial issues and environments they can face after graduation and be aware of strategies they can use to handle such challenges. Above all, reading teacher programs must strive to help student teachers move from "a focus on self to a focus on student learning and from the foundations of learning theories to their implication for teaching" (Darling-Hammond and Baratz-Snowden, 2007, p. 115). Further research on the impact of literacy coaching, for instance, the interactions of BG and her colleagues, is needed to improve quality teaching and learning.

In addition, professional development (e.g., workshops, mentoring, round table talks, sharing stories and struggles with colleagues) significantly helps teachers gain more knowledge and confidence to cope with the challenges of mandates. Moreover, teachers as agents of change are urged to examine and question themselves about what they truly believe and practice in the classroom, in essence, to become reflective practitioners. The experiences of JA, BG, Linda, and Melinda reflect the differing ways that today's teachers, literacy specialists, and coaches are navigating through and around the mandates in their classroom settings.

\section{Acknowledgements}

The authors express appreciation to the group of literacy researchers involved in the multi-phase study: Barbara Laster, Terry Deeney, Cheryl Dozier, Penny Freppon, Debra Gurvitz, Stephanie McAndrews, Dolores Gaunty-Porter, Aimee Morewood, Lee Dubert Tysseling, Barbara Walker, Verlinda Angell, Lillian McEnery, and Charline Barnes .

\section{References}

Bogdan, R. C., \& Biklen, S. K. (1992). Qualitative research for educators: An introduction to theory and methods (2nd ed.). Boston, MA: Allyn \& Bacon.

Bransford, J., \& Schwartz, D. (1999). Rethinking transfer: A simple proposal with multiple implications. Review of Research in Education, 24,(1), 61-100.

Buly, M. R., \& Rose, R. R. (2001). Mandates, expectations, and change. Primary Voices 
$K-6,9,3-6$.

Cheng, L. (2000, April). Washback or backwash: A review of the impact of testing on teaching and learning. Paper session presented at the annual meeting of the American Educational Research Association, New Orleans, LA.

Cobb, J. (2001). The effects of an early intervention program with preservice teachers as tutors on the reading achievement of primary grade at-risk children. Reading Horizons, 41(3), 155-173.

Crawford, P. A. (2004). "I follow the blue..." A primary teacher and the impact of packaged curriculum. Early Childhood Education Journal, 32, 205-210.

Darling-Hammond, L., \& Baratz-Snowden, J. (2007). A good teacher in every classroom: Preparing the highly qualified teachers our children deserve. Educational Horizons, 111-132.

Deeney, T., Dozier, C., Laster, B., Angell, V., Barnes, C., Carter, C., Cobb, J., Hill, M. McAndrews, S., McEnery, L., Sargent, S., Walker, B., \& Freppon, P. (2005, December). A national look at teacher preparation in reading clinics/literacy labs. Alternative session presented at the 55th annual meeting of the National Reading Conference, Miami, FL.

Freppon, P., Deeney, T., Dozier, C., Laster, B., Allman, T., Angell, V., Barnes, C., Cobb, J., Dubert, L., Gaunty-Porter, D., Gurvitz, D., McAndrews, S., McEnery, L., Morewood, A., Sargent, S., \& Walker, B. (2006, December). Life after reading clinic/literacy lab: Teachers reflect on practice. Alternative session presented at the 56th annual meeting of the National Reading Conference, Los Angeles, CA.

Hayes, W. (2006). The progressive education movement: Is it still a factor in today's schools? New York, NY: Rowman \& Littlefield Education.

Hoffman, J. V., \& Pearson, P. D. (2000). Reading teacher education in the next millennium: What your grandmother's teacher didn't know that your granddaughter's teacher should. Reading Research Quarterly, 35, 28-44.

Hoffman, J., Assaf, L., \& Paris, S. (2001). High-stakes testing in reading: Today in Texas, tomorrow? The Reading Teacher, 54, 482-492. http://www.ed.gov/nclb/overview/intro/execsumm.html

Hoffman, J. V., Roller, C., Maloch, B., Sailors, M., Duffy, G., \& Beretvas, S. N. (2005). National Commission on Excellence in elementary teacher preparation for reading instruction. The Elementary School Journal, 105, 267-287.

Jennings, J. (1995). School reform based on what is taught and learned. Phi Delta Kappan, 76, 765-769.

Johnson, M. (2007). The meaning of the body: Aesthetics of human understanding. Chicago, IL: The University of Chicago Press.

Jones, M. G., Jones, B. D., Hardin, B., Chapman, L, Yarbrough, T., \& Davis, M. (1999). The impact of high-stakes testing on teachers and students in North Carolina. Phi Delta Kappan, 81(3), 199-203.

Laster, B., Johnston, P., \& Rogers, R. (2006). Critical literacy critical teaching: Tools for preparing responsive teachers. New York, NY: Teachers College Press.

Merriam, S. B. (1998). Qualitative research and case study applications in education. San Francisco, CA: Jossey-Bass Inc. 
McColskey, W., \& McNunn, N. (2001). Strategies for dealing with high-stakes state tests. Phi Delta Kappan, 82(2), 115-121.

Snow, C. E., Griffin, P., \& Burns, M. S. (2005). Knowledge to support the teaching of reading: Preparing teachers for a changing world. San Francisco, CA: JosseyBass.

Tannen, D. (1989). Talking voices: Repetition, dialogue, and imagery in conversational discourse. New York, NY: Cambridge University Press.

Tannen, D. (2007). Talking voices: Repetition, dialogue, and imagery in conversational discourse (2nd ed.). Cambridge, UK: Cambridge University Press.

Vygotsky, L.S. (1978). Mind and society: The development of higher mental processes. Cambridge, MA: Harvard University Press.

Author Biographies

Jeanne Cobb is Professor of Literacy Education at Coastal Carolina University. She has $30+$ years in education as elementary teacher, reading specialist, Title I teacher, university professor, and reading clinic director. She is the co-author of the text, Historical, Theoretical and Sociological Foundations of Reading in the United States.

Stephan Sargent is a professor of reading/literacy education at Northeastern State University near Tulsa, Oklahoma. He serves as the director of the Northeastern State University Reading Clinic and also teaches undergraduate and graduate courses for pre and in-service educators in reading/literacy.

Chitlada Patchen is currently a freelance literacy educator; working with homeschool parents. She has 24 years in education as a secondary teacher, university professor, and reading clinic mentor. 


\section{Appendix A}

Table 1

Local School/District Mandates - Research Sites Reporting

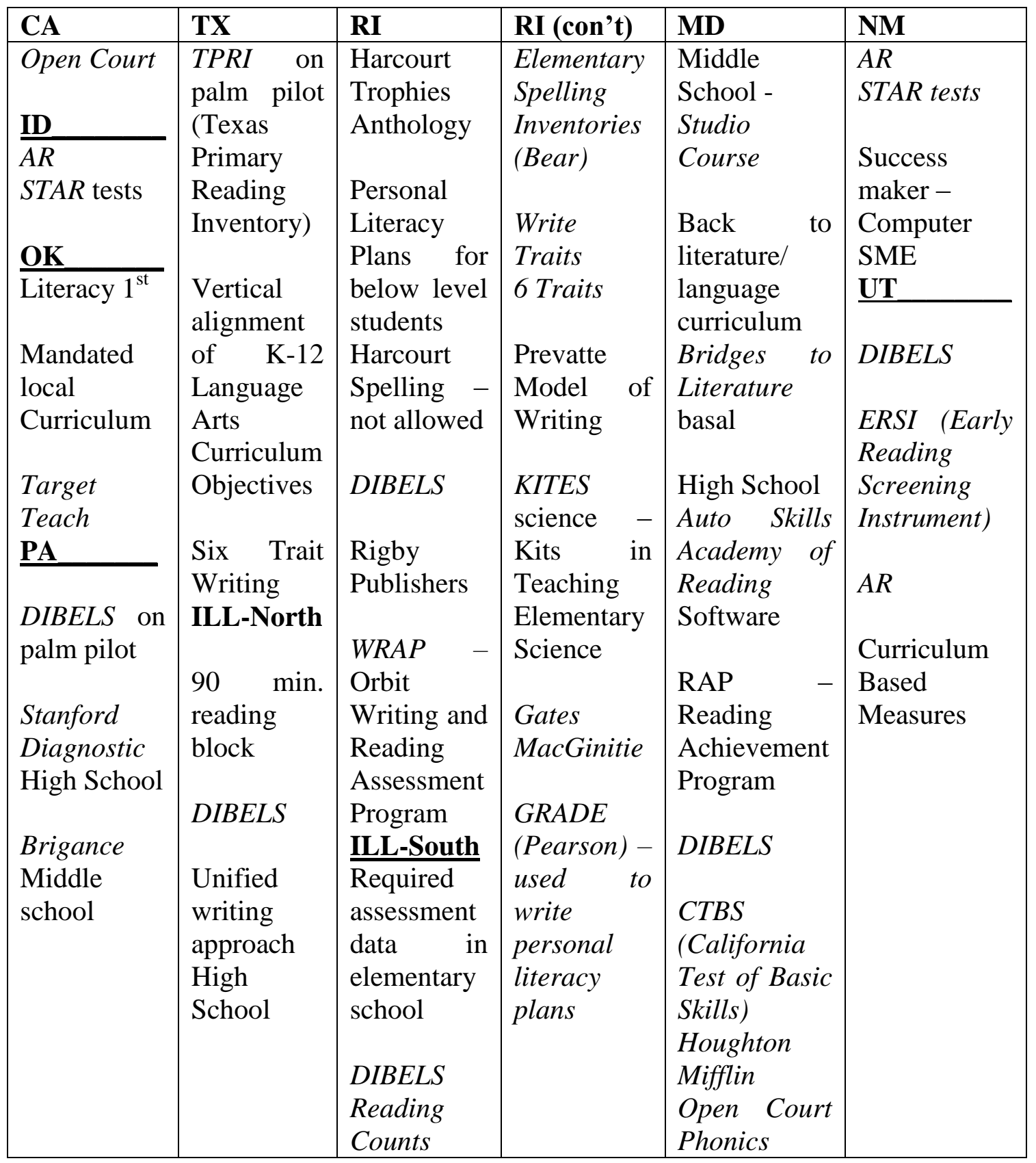




\section{Appendix B}

Table 2

State Mandates - Research Sites Reporting

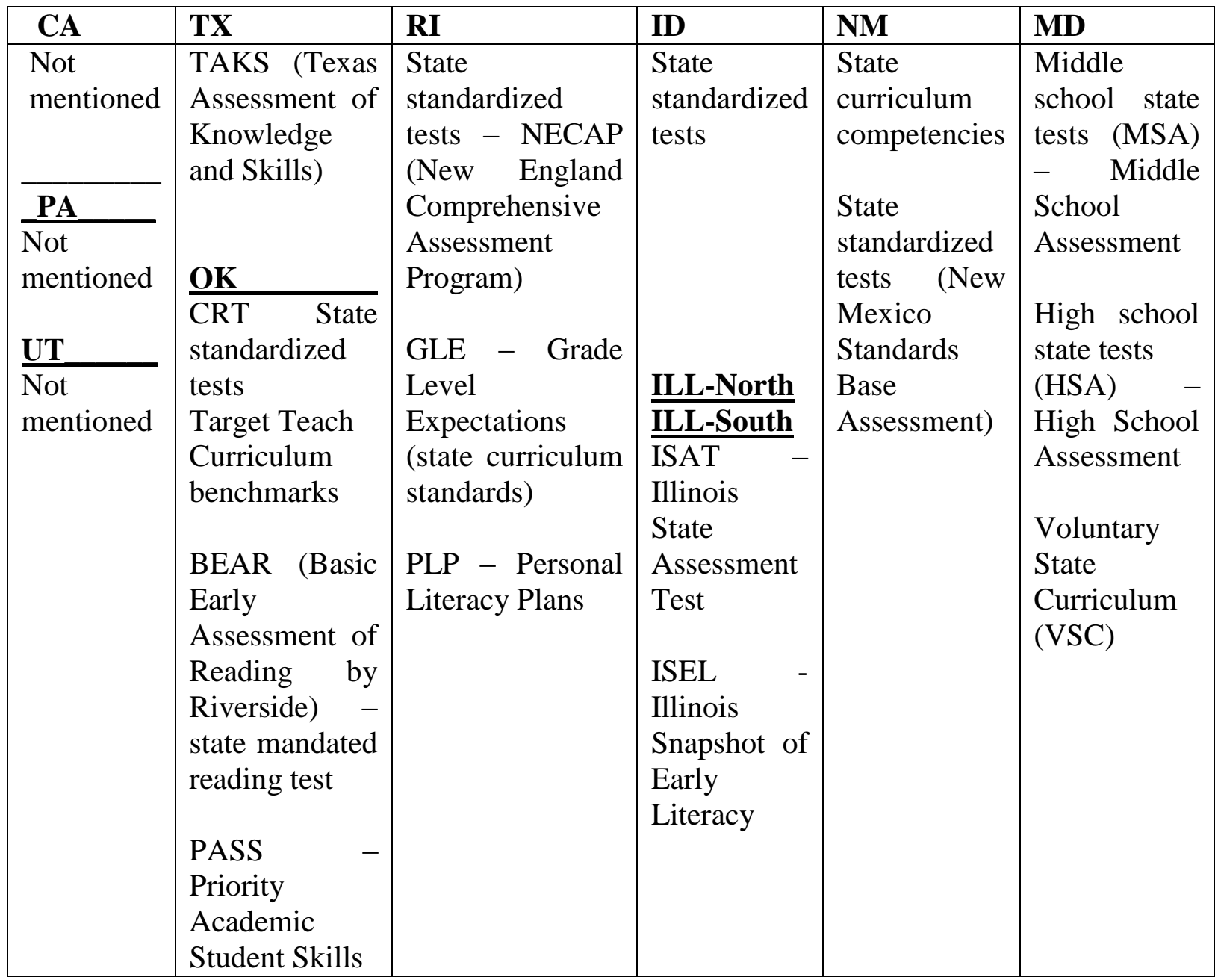




\section{Appendix C}

Table 3

Federal Mandates - Research Sites Reporting

\begin{tabular}{|l|l|l|l|l|l|}
\hline CA/OK & TX/UT & RI/PA & ID/MD/NM & ILL-North & $\begin{array}{l}\text { ILL- } \\
\text { South }\end{array}$ \\
\hline $\begin{array}{l}\text { Not } \\
\text { mentioned }\end{array}$ & Not mentioned & Not mentioned & NCLB & NCLB & $\begin{array}{l}\text { IEP } \\
\text { AYP } \\
\text { (adequate } \\
\text { yearly } \\
\text { progress) }\end{array}$ \\
\hline
\end{tabular}

